\title{
Attitude Towards Third Gender: A Case Study Of Southern Punjab, Pakistan
}

\author{
Iram Batool \\ Department of Applied Psychology \\ Bahauddin Zakariya University \\ Muhammad Saqib \\ School of Global and Urban Studies \\ RMIT University, Melbourne, Australia
}

\author{
Abdul Sattar Ghaffari \\ Institute for Financial Studies, School of Mathematics \\ Shandong University
}

\begin{abstract}
Transgender community faces insulting remarks and people treat them in a bad way. Discrimination is being faced by transgender at all levels such as at school, in family, at places where they live. The purpose of the present study was to explore the attitude of people towards third gender. A sample of 600 were selected through purposive sampling and snow ball sampling techniques. Data was collected from Two cities of Pakistan Sahiwal and Multan. Demographic variables of participants used in this research are age, gender, monthly income, qualification and marital status. Attitude towards Hijras scale was used in this research. Results showed that females have more acceptances of Hijra's (transgender) rights and status as compared to males. Males and females don't want any close relationship with Hijras (transgender).Sexual issues (SI) are significant in males as compared to females. Education has more impact on people's attitude towards Hijra community. People belonging to religious groups have more negative attitude towards Hijras as compared to other groups.
\end{abstract}

Keywords: Transgender, Attitude of People, Third Gender.

$$
\begin{aligned}
& \text { تلخيص }
\end{aligned}
$$

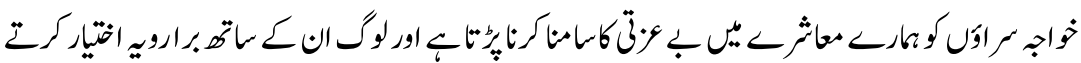

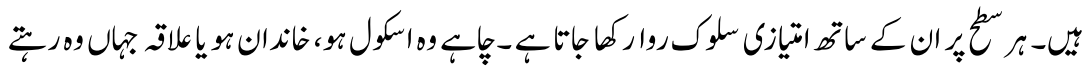

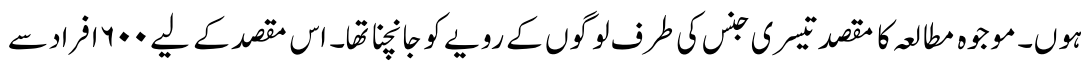

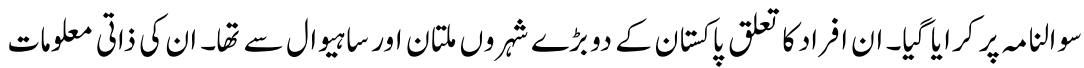

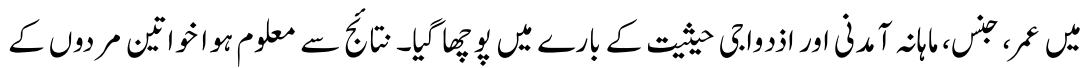

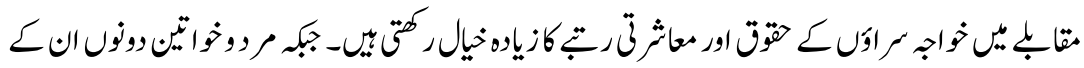




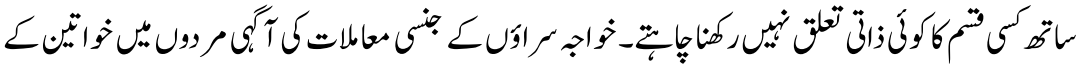

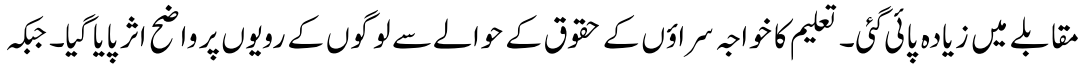

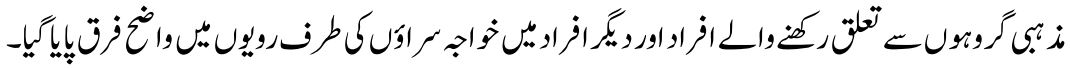

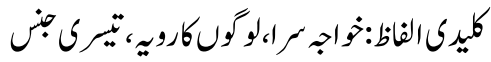

\section{Introduction}

Transgender is used as an umbrella term which is defined as looks and gender identity of people that differ from the cultural boundaries of gender related with individual's birth sex i.e., female or male (Davidson, 2007; Valentine, 2007).This umbrella term also consisted of individuals whose individuality is outside the binary gender in which the only categories included are boys/men and girls/women or somewhere between girl/woman and boy/man. These types of people may refer to themselves as gender queer, gender independent, gender nonconforming, gender fluid, gender non-binary or gender creative (Vance, Ehrensaft, \& Rosenthal, 2014). The transgender define their individuality as gender queer, transgender man, transgender woman, femme queen, butch queen, bi-gender and they try to express their individuality in different ways, which may differ from culture to culture according to socioeconomic status, racial/ethnic background and their place of residence (Valentine, 2007). Socially transition for example change their name, gender identity, pronoun and medically transition for example use techniques like surgery, cross-sex hormones in order to line up their individuality according to gender expression (Davidson, 2007). Transgender people in US are considered deviant because their individuality is not according to the assigned birth sex and due to this they experience stigma (Bockting et al., 2013; Grant et al., 2011; Lombardi et al., 2002). Population of transgender assessed is $0.03 \%$ to $0.05 \%$ (Conron et al., 2012; Gates, 2011; Reisner et al., 2014a).

In the year of 2009 in Pakistan, when the transgender community was first granted their official CNIC's, the estimated number of CNIC card registered under the category of transgender was 4000 . However, this number is not a correct representation of the transgender community. According to a report from United Nations AIDS (UNAIDS), the current estimated number of the transgender community is around 150,000. The report also suggests that the total number of sex workers among this population is around 50-60,000. Trans Action Alliance/Blue Veins estimate total number of 40-50,000 transgender in the province of Khyber Pakhtunkhwa. Gender Interactive Alliance (GIA) in Karachi estimates the transgender population around 15- 20,000 (Nazir \& Yasir (2015). 
Number of theories exist which tell about the existence of transgender but some scientific consent still needed. Most of the theories on transgender are psychological, cultural, biological and medical. Psychology theorists said that there is a link between the structure of brain and the identity of a person, According to the cultural theory, identification of individuals varies from culture to culture, people defined in two categories by some cultures, while some cultures define people in three categories depending on their roles in society and what their status was at birth. According to biological theorists, normal sex of a person is determined by his/her number of chromosomes. If the number of chromosomes is not normal then it is called as intersex or a transgender. Medical theorists believed that hormonal imbalance in mother's womb result in intersex or transgender. While feminist theory accepted the identity of transgender (MacDonald, 1998).

It is a well-established fact that transgender community has been a serious target of hate crimes for the past countless years. Due to the lack of awareness and sensitivity in our society, they are constantly harassed and are a victim of resentment, ridicule, malice and hostility from fellow citizens. In Pakistan, on August 9, 2016, a transgender woman named Sumbal was shot thrice in her abdomen when she tried to resist abduction and rape. Later when she was found by her friends and was taken to the hospital, the doctors and nurses refused to treat her because they were uncertain whether to admit her in the male or female ward. During this useless battle, Sumabal lost the bigger battle, her life. This incident screams the blatant neglect of not just the Police but also the medical staff members who are equal culprits in the rescinding their basic human rights ("Pakistan: Attacks on Transgender Women Surge",2016).

Another case occurred in Pakistan last year. Ayesha, a 22 year old transgender woman reported her house was broken into. She stated that a mob broke robbed her house and threatened her life. But when she went to the Police station to get file an FIR, the guard wouldn't even let her inside the station. The Police started mocking her at the doors of the Police station. No one was ready to pay any heed to her complaint just because she was a transgender. Trans Action Alliance's vice president, Paro, reported during a news conference that the SHO of the Nowshera cantonment SHO had called several members of their community and had ordered them to leave the city. Not just this, he kept them in the holding cell for 10 hours and later and they were subjected to physical violence as well as sexual abuse ("Pakistan: Attacks on Transgender Women Surge",2016).

Unfortunately, there is a very low tolerance rate for the third gender not just in our society but universally as well. They are a constant victim of derogatory behaviour and snide remarks from a very young age. Their acceptance amongst their peers is minimal from the beginning which leads to some major self-esteem 
and mental health issues. Most of the times this gender is ambushed at the hands of their own family by being disregarded or thrown out of the house at a very tender age. These people are subjected to bullying more than a person from the binary gender system is. The third gender is barely accepted in our society which naturally effects their acceptance at school or at workplace. Since they are religiously bullied in schools, they are most likely to drop out and resort to professions that are deemed highly abominable by the society (Nazir \& Yasir, 2016).

\section{Literature Review}

People whose gender identity is not according to the suggested cultural setups of male or female (gender nonconformity), face high level of stigma, have low wellbeing, face rejection (Rodgers, 2017). Among sexual minorities gender nonconformity appears as a powerful predictor of poor well-being and higher level of stigmatization as compared to sexual orientation (Baams, Beek, Hille, Zevenbergen \& Bos, 2013). Development, mental health, psychological adjustment of sexual minority is adversely affected by stigmatization and increased the health risk behaviors (Toomey, Ryan, Diaz, Card \& Russell, 2010) (Bontempo \& d'Augelli, 2002). Minority stress model by Meyer (2003) explained that how psychological well-being of sexual minorities are affected by different factors. Some of the stressors that badly affect the LGBTQ (lesbian, gay, bisexual, transgender, and questioning) community are discrimination, expected homonegativity, concealing one's sexual orientation and internalized homonegativity(Meyer, 2003).

Discrimination is being rejected by their family members, friends, and being bullied at schools, and face prejudice (Birkett, Newcomb \& Mustanski, 2015; Russell, Ryan, Toomey, Diaz \& Sanchez, 2011). Expecting to experience rejection and prejudice events is another major stressor (Birkett, Newcomb \& Mustanski, 2015). Concealment means try to hide LGBTQ position in society. They are very conscious about self-monitoring and try to imitate the gender behaviors which are expected by the society. Low self-esteem and moods are commonly reported outcomes (Birkett, Newcomb \& Mustanski, 2015). Internalization of negative views of the society based on the social stigma forced transgender to think less about themselves (Lewis, R. J., Milletich, Kelley \& Woody, 2012).

Higher the level of stress and poor psychosocial health is reported by Cox, Dewaele, Van Houtte \& Vincke, 2010. Higher levels of depression and suicide rates were reported among LGBT students (Hillard, Love, Franks, Laris \& Coyle, 2014, Russell, Ryan, Toomey, Diaz, \& Sanchez, 2011, Kolbert, Crothers, Bundick, Wells, Buzgon, Berbary \& Senko, 2015). Anti-bullying campaigns 
greatly improved the environment in schools for these students (Russell, Kosciw, Horn \& Saewyc (2010; Rodgers, 2017).

People with gender nonconformity around the world face the stigma throughout their lives and become vulnerable to discrimination and prejudice. They hesitate to reveal their gender individuality at health care centers and it increases level of anxiety. A survey on National Transgender Discrimination revealed that due to the gender identity $19 \%$ of the participants refused care, $28 \%$ verbally harassed transgender and $2 \%$ were physically attacked while taking medical care (Grant, Mottet, Tanis, Herman, Harrison \& Keisling, 2010). Such negative interactions lead to avoid or delay in medical checkups and increases the bad experience towards the society. High level of health risks were also reported (Sanchez, Sanchez \& Danoff, 2009).

A nationwide survey on more than 7800 LGBT, results showed that because of the sexual orientation $55.5 \%$ felt unsafe at school, where as $36.2 \%$ faced physical harassment, 74.1\% experienced verbal harassment and 49\% suffered from cyber bullying (Kosciw, Greytak, Bartkiewicz, Boesen \& Palmer, 2012). Continuous bullying in the lives of transgenders was also investigated (Sherriff, Hamilton, Wigmore \& Giambrone, 2011;Kolbert, Crothers, Bundick, Wells, Buzgon, Berbary \& Senko, 2015). Transgender have lower grades in schools, skip their classes and try to avoid school (Hillard, Love, Franks, Laris \& Coyle, 2014).

Different names are given to transgender in Pakistan such as Hijra, Murat, Khawaja Sara or Khusra. Transgender from the childhood face insulting remarks and people treat them in bad way. Discrimination is being faced by transgender at all levels such as at school, in family, at places where they lived (Nazir \& Yasir, 2016). Most of the people in Pakistan, due to the old traditions don't consider them as a part of their society. According to the estimation, the total population of transgender ranged from 350,000-500,000.Different studies showed that one out of fifty children born is bi-gender. Approximately $2 \%$ of population of Pakistan is transgender (Sarfraz, 2017). Transgender in Pakistan are unable to get basic facilities of life such as good education, good jobs etc. Most of them use to dance in weddings, beg or work as sex workers. They suffer from sexually transmitted diseases; they find difficulty in accessing healthcare facilities. Recently in Peshawar a transgender was shot by gun eight times and no health care facility was provided to her as a result she died (Fawad, 2016).

Nazir \& Yasir (2016) concluded that transgender do not live in fixed place, rather they keep on changing their residence. The main reason is to keep a distance from those people who know them and their families. Their adopted professions such as dancing, begging are also not acceptable by their surroundings so they keep changing their residences and feel independent. Families of transgender feel 
ashamed of their presence and ask them to avoid contact with them. Parents of transgender suffer from huge stigma especially in Pakistani society. Low literacy rate in our society forced parents of transgender to send their child to eunuch community and deprived from good facilities of education, living and earning. It was found that population of uneducated eunuchs in Pakistan is $79 \%$. A very common reason for illiteracy is sexual and verbal abuse, lack of finances, being beaten up by the teachers and gender discrimination (Nazir \&Yasir, 2016).

Rude remarks and the discrimination that transgender faced by their school fellows and neighbours forced them to stay apart from the main stream. The Constitution of Pakistan emphasize on the equal rights to all citizens. Provisional and federal governments talked about equal share of transgender in inheritance, education and employment. A right to vote was also given by Supreme Court of Pakistan to transgender community and for the first time in 2013, five transgender contested the elections (Nazir, Yasir, 2016).

McGuire, Doty, Catalpa, Ola (2016) researched Body Image in young Transgender people. This was a qualitative research and a community based research which generated data through in-depth interviews from 90 transgender from United States, Canada and Ireland. With the use of queer perspective, qualitative analysis disclosed two conceptual categories: Body satisfaction and body dissatisfaction. The results revealed that there were greater deal of dissatisfaction with their body image which was a direct cause of great distress and self plus public criticism. The participants reported to not feel comfortable in their bodies but they actually felt that they are trapped inside of someone else's body and lead a different life. They accounted for less acceptance and more bashing from their peers as well as their community. This derogatory behaviour lead to them feeling ashamed of their appearance and developing body dissatisfaction.

Grift, Kreukels, Elfering et al. (2016) explored the results of a pre and post operation for mastectomy of 33 transgender in Body Image in Transmen. Body satisfaction of the participants was measured through Body Image Scale for Transsexuals, Body Image Quality of Life Scale and Rosenberg Self-Esteem Scale. These participants were measure 6 months pre and post-operative period. The results showed that after the operation, these transsexuals had a greater sense of body satisfaction and a higher and a more positive self-esteem. They could match their minds with their body now, so they didn't feel conflicted with their bodies anymore. There seemed more acceptance for them from their peers since they fell more in one of the category of the binary gender system.

Neumann and Wolfradt (2001) explored whether postoperative male-to-female transsexuals differ I with regards to measures of self and body image from a non- 
transsexual control group. The total sample size included 90 people in total among which 30 were transsexuals, 30 were women and 30 were men who were a part of the control group in this research. Both the groups completed self-report measure on self-esteem, body image, gender identity traits and depersonalization. The results depicted that the transsexuals and the male participants rated higher on the selfesteem and body image dynamics than the females. There were no differences between both the groups in terms of depersonalization. Naturally, the females and the transsexuals described themselves more feminine than the mal participants. And regarding sex-role orientation, more bi-gendered or transgendered traits were found among the transsexuals than in the control group.

The main aim of the study was to explore the attitude towards transgender community. Furthermore it was aimed to investigate gender differences on level of Social Distance, Right \& Status and Sexual Issues about third gender. Moreover the current study aimed to investigate the difference of attitude among people having different educational background and level of religious practices.

\section{Objectives of Study}

The main objectives of the study are:

1. To explore the attitude of individuals from different walks of life towards transgender community.

2. To investigate gender differences on level of Social Distance, Right \& Status and Sexual Issues about third gender.

3. To investigate the attitudes of people towards transgender from different educational backgrounds.

4. To find out the religious group's attitude towards transgender community.

\section{Methodology}

\section{Participants}

A sample of 600 participants of age range 18-70 years were selected through convenient sampling technique. Both males and females participants belong to different walks of life were included in the sample. Data was collected from two Districts of southern Punjab i.e. Sahiwal and Multan.

\section{Instruments}

\section{Attitude towards Hijra Scale (ATH)}

Attitude towards Hijras Scale developed by Humaira Jami (2015) was used for data collection. This scale measured three factors. Factor I is "Right and Status RS" referred to the beliefs, feelings, behaviours and behavioural intentions 
extended towards providing basic human rights to Hijras including right for occupational opportunities and right to be loved and accepted. This included 13 items (no. 7,8,9,10,22,24,25,27,28,29,30,31,32 in final version).

Factor II is termed as Social Distance (SD) referred to how much closeness a person can accept in having any relationship with Hijras for example as a neighbor, colleague, relative, interacting or talking to or about them, accepting as a leader in electoral process, so on. This included 11 items (no. 13, 14, 15, 16, 17, $18,19,20,21,23,26$ in final version).

Factor III is named as 'Sexual Issues' (SI) referred to the attitudes towards different sexual issues related to Hijras like promiscuous behavior, spreading HIV/STDs and homosexuality, indulging in sex business, transgenderism, etc. It included 8 items (no. 1, 2, 3, 4, 5, 6, 11, 12 in final version). On the basis of three component model of attitudes based on behavioural intentions (Allport as cited in Hogg \& Vaughan, 2005), 8 items (items 13, 14, 15, 17, 19, 20, 21, 32) pertained to behavioral intentions and remaining revolved around cognitive, feeling, and behavioral components.

\section{Procedure}

Participants were approached at their places, purpose of the study was explained to them. Confidentiality of the information was ensured to participants. All the respondents filled the informed consent; it took 10-12 minutes to fill out the questionnaire.

\section{Results}

The data was analyzed on the basis of study objectives. The demographic details of the participants were also.

Table: 1

Demographic attributes of whole sample $(\mathrm{N}=600)$

\begin{tabular}{|l|c|c|}
\hline Demographic Variable & Frequency & Percentage \\
\hline Groups & 120 & 20 \\
\hline Working Class & 120 & 20 \\
\hline Students & 120 & 20 \\
\hline Religious Group & 120 & 20 \\
\hline House wives Retired & 120 & 20 \\
\hline Physical Handicapped & 384 & 64 \\
\hline Age & 150 & 25 \\
\hline $18-35$ &
\end{tabular}




\begin{tabular}{|c|c|c|}
\hline $54-65$ & 66 & 11 \\
\hline \multicolumn{3}{|l|}{ Gender } \\
\hline Male & 336 & 56 \\
\hline Female & 42 & 42 \\
\hline \multicolumn{3}{|l|}{ Qualification } \\
\hline Matriculation & 116 & 19.3 \\
\hline Intermediate & 102 & 17 \\
\hline Bachelor & 110 & 18.3 \\
\hline Master & 222 & 37 \\
\hline Others & 50 & 8.3 \\
\hline \multicolumn{3}{|l|}{ M Income } \\
\hline $10,000-30,000$ & 190 & 31.6 \\
\hline $31,000-60,000$ & 279 & 46.5 \\
\hline $61,000-90,000$ & 57 & 9.5 \\
\hline $91,000-1,20,000$ & 74 & 12.3 \\
\hline \multicolumn{3}{|l|}{ Marital_Status } \\
\hline Married & 346 & 57.7 \\
\hline Un-married & 254 & 42.3 \\
\hline \multicolumn{3}{|l|}{ F_Interaction_H } \\
\hline Daily & 54 & 9 \\
\hline Once a month & 252 & 42 \\
\hline Once a year & 224 & 37.3 \\
\hline Never & 70 & 11.7 \\
\hline \multicolumn{3}{|c|}{ N_Prayers_Offer } \\
\hline 5 prayers & 252 & 42 \\
\hline 4 prayers & 84 & 14 \\
\hline 3 prayers & 100 & 16.7 \\
\hline 2 prayers & 100 & 10 \\
\hline 1 prayers & 46 & 7.7 \\
\hline None & 58 & 9.7 \\
\hline \multicolumn{3}{|l|}{ Fasting_HM } \\
\hline Whole & 362 & 60.3 \\
\hline Partially & 182 & 30.2 \\
\hline None & 56 & 9.3 \\
\hline \multicolumn{3}{|l|}{ P_Zakat } \\
\hline$\overline{\mathrm{Yes}}$ & 442 & 73.7 \\
\hline No & 158 & 26.3 \\
\hline
\end{tabular}

Demographic sheet was designed to get information about gender, age, family's monthly income, marital status. As indicator of religiosity no. of prayers offered daily, fasting in holy month of Ramadhan [ninth month of Islamic year], and paying Zakat [offering $2.5 \%$ of share in property to poor people] rated as 0 for $d o$ 
not offer to 5 regularly offer were used. Participants had different educational level (Table 1). Reliability of the scale was measured (Table 2).

Table: 2

Cronbach's alpha of scales

\begin{tabular}{|l|c|c|}
\hline Scale & Cronbach's Alpha & Items No. \\
\hline ATH & $\mathbf{. 7 3 8}$ & $\mathbf{3 2}$ \\
\hline
\end{tabular}

Table: 3

Mean, standard deviation and p-value of gender groups on right \& status

(R_S)

\begin{tabular}{|l|c|c|c|c|c|c|}
\hline Scale & Gender & N & M & SD & T & P \\
\hline \multirow{2}{*}{ ATH (R_S) } & Male & 336 & 52.92 & 7.70 & -4.01 & $.000^{*}$ \\
\cline { 2 - 5 } & Female & 264 & 55.21 & 5.85 & & \\
\hline
\end{tabular}

$\mathrm{P}=(.005<0.05) \mathrm{R} \_\mathrm{S}=$ Right and Status

Table 3 shows gender difference on Right \& Status $\left(R \_S\right)$ and results revealed that there is a significant gender difference on this domain. Mean scores of females $(\mathrm{M}=55.21)$ is higher than males $(\mathrm{M}=52.92)$. The difference between two groups was significant $(\mathrm{P}<0.05)$ which shows females have more acceptance about hijra's right and status as compare to males.

Table: 4

Mean, standard deviation and p-value of gender groups on social distance (S_D)

\begin{tabular}{|l|c|c|c|c|c|c|}
\hline Scale & Gender & N & M & SD & T & P \\
\hline \multirow{2}{*}{ ATH (S_D) } & Male & 336 & 32.00 & 8.76 & 0.450 & 0.653 \\
\cline { 2 - 5 } & Female & 264 & 32.32 & 8.48 & & \\
\hline
\end{tabular}

$\mathrm{P}(0.653>0.05) \mathrm{S} \_\mathrm{D}=$ Social Distance

Table 4 shows gender difference on Social Distance $\left(S \_D\right)$ and results revealed that there is no significant gender difference on this domain. Mean scores of females $(M=32.32)$ is higher than males $(M=32.00)$ but the difference between two groups was not statistically significant $(\mathrm{P}>0.05)$. Results revealed that females and males have no difference on this domain which means both don't want any close relationship towards Hijras.

Table 5

Mean, standard deviation and p-value of gender groups on sexual issues $(\mathrm{S}$ _I)

\begin{tabular}{|l|c|c|c|c|c|c|}
\hline Scale & Gender & N & M & SD & T & P \\
\hline \multirow{2}{*}{ ATH (S_I) } & Male & 336 & 23.95 & 2.66 & 4.90 & $0.000^{*}$ \\
\cline { 2 - 5 } & Female & 264 & 22.85 & 2.81 & & \\
\hline
\end{tabular}

$\mathrm{P}(.001<0.05), \mathrm{S} \_\mathrm{I}=$ Sexual Issues 
Table 5 shows gender difference on Sexual Issues (S_I) and results revealed that there is a significant gender difference on this domain. Mean scores of males $(M=23.95)$ is higher than females $(M=22.85)$. The difference between two groups was significant $(\mathrm{P}<0.001)$ which shows males have more awareness about hijra's sexual issues (SI) as compare to females.

Table: 6

One way ANOVA analysis on education

\begin{tabular}{|l|c|c|c|c|c|}
\hline Variables & SS & DF & MS & F & P \\
\hline Between groups & 2574.2 & 4 & 643.5 & 9.662 & .000 \\
\hline Within groups & 39626.3 & 595 & 66.6 & & \\
\hline Total & 42200.5 & 599 & & & \\
\hline
\end{tabular}

Note. $\mathrm{P}>0.05, \mathrm{Edu}=$ education

Results in table 6 showed that there were significant differences between education groups of participants on attitude $(\mathrm{F}=9.662, \mathrm{p}=<.001)$.

Table: 7

One way ANOVA analysis between different religious groups

\begin{tabular}{|l|c|c|c|c|c|}
\hline Variables & SS & DF & MS & F & P \\
\hline Between groups & 3389.7 & 4 & 847.4 & 12.991 & .000 \\
\hline Within groups & 38810.9 & 565 & 65.2 & & \\
\hline Total & 42200.6 & 599 & & & \\
\hline
\end{tabular}

Note: $\mathrm{P}<0.05$,

Table 7showed that there was a significant differences between different religious groups on attitude $(\mathrm{F}=9.662, \mathrm{p}=<.001)$.

\section{Discussion}

The aim of the study was to explore attitude towards third gender. Furthermore it was aimed to explore if there is any gender difference and difference among different age groups. Moreover it was aimed to explore the difference of attitude towards transgender among people having different educational background. Even though, Hijra community shows their existence in Pakistan. Literature shows that there is a dearth of related research evidence. A very few work has been done on third gender issue. That dearth of work might be of many reasons like due to some Islamic ideology people do not like to work on that phenomenon.

Limited findings talked about non-heterosexual identity, behaviour and stigma that discourages investigators to explore LGBTs (Hughes \& Eliason, 2002). Present study was conducted to explore further in this area. Main focus was on attitude toward third gender and for that purpose Attitude towards Hijras (ATH) 
scale was used. Scale was consisted of three factors. First factor was named as Right \& Status (RS) as items included referred to attitude related to right for identity, mental and physical health facilities, educational and occupational opportunities and right to be loved. The results of comparison between males and females showed that females have more acceptability towards Hijras that they should get their all rights and status as they are a part of our society. This might be because of the fact that females are more emotional and sensitive to any situation as compared to males. Being a human being, all basic rights and facilities should be provided to them.

Previous investigator (Sharma, 2000; see Totman, 2003 for Kathoey of Thailand) found that these sexual minorities are isolated part of main stream society. This marginalization come up with minimum interaction between society and sexual minorities (like hijra community). It was also summarized that accessibility and strength of attitude is rooted in level of interaction and experience with the social object (see Bohner \& Wanke, 2002; Hogg \& Vaughan, 2005; King et al., 2009; Maio et al., 2006).

To get the answer to the question that how much people want to be closer to or have relationship with third gender. Second factor measured by the scaled used in this study is Social Distance (SD). Social Distance referred to how much closeness a person can accept in having any relationship with Hijras for example, as neighbors, colleague, class-fellow, relative, interacting or talking to or about them, so on. The results of the study revealed that both are not ready to have any sort of relationship with Hijras like at workplace, relative etc. Evidence of such dimension is also available in previous measures (see King et al., 2009). These findings indicated the negative attitude towards this community. This discriminative attitude is already reported by previous investigators. Discrimination is being faced by transgender at all levels such as at school, in family, at places where they lived (Nazir \& Yasir, 2016).

Third factor was Sexual Issues (SI), it refers to attitudes towards different sexual issues attached with Hijras like related to AIDS/ STDs, sex business, homosexuality and so on. The findings of this study concluded that males have more information regarding sexual issues related to this gender. This might be because of their more frequent interaction with them as compared to female. People generally blame Hijras for sexual relationships (Jami, 2005, 2012; Riaz, 1996).

Low literacy rate deeply affects the attitude of people towards Hijras. As this research reveals that literate people have positive attitude towards Hijras as compared to illiterate people. If the level of education increases the chances of positive attitude towards Hijras will also be increased. The religious group showed the hatred attitude towards Hijras of Hijras community (Jami, 2015). 
While, Miller (2015) considers that an increase in the visibility of transgender people, whether in the clinical setting or the wider community, may not bring about understanding and acceptance. However, Sharma (2000) pointed out that in western countries, transsexuals can easily live in mainstream for their ability to pass as a woman, but Hijras are quite visible and people never perceive them as woman as they look very different.

\section{Conclusions}

From the present study, we conclude that people know about hijras' rights and status. But no one wants to have any relationship with this community. Males have more information regarding their sexual issues. Majority of people believed that hijras are individuals who are born with sexual deformity. Females have less interaction than males with hijras on daily basis. Education is a dominant factor which has impacted on people's attitude towards Hijras. Groups from religious background showed different attitude towards Hijras as compared to other groups.

\section{Recommendations}

This study was conducted in one region, could be extended with larger sample. More intensive investigation is required on the problems faced by third gender which are related to such attitudes of society members. Need to investigate the factors which can play role in formulating positive attitude towards this marginalize population. It is highly recommended that transgender should be incorporated in the main stream. Positive attitudes of people can work as a bridge between this deprived population and normal population.

\section{References}

Baams, L., Beek, T., Hille, H., Zevenbergen, F. C. \& Bos, H. M. (2013). Gender Nonconformity, Perceived Stigmatization and Psychological Well-Being in Dutch Sexual Minority Youth and Young Adults: A Mediation Analysis. Archives of Sexual Behavior, vol.42:5, pp.765-773.

Birkett, M., Newcomb, M. E. \& Mustanski, B. (2015). Does it get better? A Longitudinal Analysis of Psychological Distress and Victimization in Lesbian, Gay, Bisexual, Transgender and Questioning Youth. Journal of Adolescent Health, vol.56:3, pp.280-285.

Bith-Melander, P., Sheoran, B., Sheth, L., Bermudez, C., Drone, J., Wood, W. \& Schroeder, K. (2010). Understanding Socio-Cultural and Psychological Factors Affecting Transgender People of Color in San Francisco. Journal of the Association of Nurses in AIDS Care, vol.21:3, pp.207-220. 
Bockting, W. O., Miner, M. H., Swinburne Romine, R. E., Hamilton, A. \& Coleman, E. (2013). Stigma, Mental Health and Resilience in an Online Sample of the US Transgender Population. American Journal of Public Health, vol.103:5, pp.943-951.

Bohner, G. \& Wanke, M. (2002). Attitudes and attitude change. New York: Tailor $\&$ Francis Group.

Bontempo, D. E. \& d'Augelli, A. R. (2002). Effects of At-School Victimization and Sexual Orientation on Lesbian, Gay, or Bisexual Youths' Health Risk Behavior. Journal of Adolescent Health, vol.30:5, pp.364-374.

Conron, K. J., Scott, G., Stowell, G. S. \& Landers, S. J. (2012). Transgender Health in Massachusetts: Results from a Household Probability Sample of Adults. American Journal of Public Health, vol.102:1, pp.118-122.

Cox, N., Dewaele, A., Van Houtte, M. \&Vincke, J. (2010). Stress-Related Growth, Coming Out and Internalized Homonegativity in Lesbian, Gay, and Bisexual Youth. An Examination of Stress-Related Growth within the Minority Stress Model. Journal of Homosexuality, vol.58:1, pp.117-137.

Davidson, M. (2007). Seeking Refuge Under the Umbrella: Inclusion, Exclusion, and Organizing within the Category Transgender. Sexuality Research and Social Policy, vol.4:4, pp.60-80.

Fawad, A. S. (2016). Transgender Health. Retrieved from Dawn.com: https://www.dawn.com/news/1300323

Grant, J. M., Mottet, L., Tanis, J. E., Harrison, J., Herman, J. \& Keisling, M. (2011). Injustice at Every Turn: A Report of the National Transgender Discrimination Survey. National Center for Transgender Equality.

Grant, J. M., Mottet, L., Tanis, J. E., Herman, J., Harrison, J. \& Keisling, M. (2010). National Transgender Discrimination Survey Report on Health and Health Care: Findings of a Study by the National Center for Transgender Equality and the National Gay and Lesbian Task Force. National Center for Transgender Equality.

Hillard, P., Love, L., Franks, H. M., Laris, B. A. \& Coyle, K. K. (2014). They Were Only Joking: Efforts to Decrease LGBTQ Bullying and Harassment in Seattle Public Schools. Journal of School Health, vol.84:1, pp.1-9. 
Hogg, M. A. \& Vaughan, G. M. (2005). Social Psychology (4th ed.). Pearson Prentice Hall.

Hughes, T. L. \& Eliason, M. (2002). Substance Use and Abuse in Lesbian, Bisexual and Transgender Populations. The Journal of Primary Prevention, vol.22:3, pp.263-298.

Jami, H. (2005). Condition and Status of Hijras (Transgender, Transvestites etc.) in Pakistan. In Sexualities, Genders and Rights in Asia', 1st International Conference of Asian Queer Studies Retrieved September (Vol. 5, p. 2006).

Jami, H. (2012). Attitude towards Hijras and their Reciprocal Perceptions (Unpublished Doctoral Dissertation). National Institute of Psychology, Quaid-i-Azam University, Islambad, Pakistan.

Jami, H., \& Kamal, A. (2015). Measuring Attitudes toward Hijras in Pakistan: Gender and Religiosity in Perspective. Pakistan Journal of Psychological Research, vol.30:1.

King, M. E., Winter, S. \& Webster, B. (2009). Contact Reduces Trans-Prejudice: A Study on Attitudes towards Transgenderism and Transgender Civil Rights in Hong Kong. International Journal of Sexual Health, vol.21, pp.17-34.

Kolbert, J. B., Crothers, L. M., Bundick, M. J., Wells, D. S., Buzgon, J., Berbary, C. \& Senko, K. (2015). Teachers' Perceptions of Bullying of Lesbian, Gay, Bisexual, Transgender and Questioning (LGBTQ) Students in a Southwestern Pennsylvania sample. Behavioral Sciences, vol.5:2, pp.247-263.

Kosciw, J. G., Greytak, E. A., Bartkiewicz, M. J., Boesen, M. J. \& Palmer, N. A. (2012). The 2011 National School Climate Survey: The Experiences of Lesbian, Gay, Bisexual and Transgender Youth in Our Nation's Schools. Gay, Lesbian and Straight Education Network (GLSEN). 121 West 27th Street Suite 804, New York, NY 10001.

Lewis, R. J., Milletich, R. J., Kelley, M. L. \& Woody, A. (2012). Minority Stress, Substance Use and Intimate Partner Violence among Sexual Minority Women. Aggression and Violent Behavior, vol.17:3, pp.247-256.

Lombardi, E. L., Wilchins, R. A., Priesing, D. \& Malouf, D. (2002). Gender Violence: Transgender Experiences with Violence and Discrimination. Journal of Homosexuality, vol.42:1, pp.89-101. 
MacDonald, E. (1998). Critical Identities: Rethinking Feminism through Transgender Politics. Atlantis: Critical Studies in Gender, Culture \& Social Justice, vol.23:1.

McGuire, J. K., Doty, J. L., Catalpa, J. M. \& Ola, C. (2016). Body Image in Transgender Young People: Findings from a Qualitative, Community Based Study. Body Image, vol.18, pp.96-107.

Miller, L. R. \& Grollman, E. A. (2015, September). The Social Costs of Gender Nonconformity for Transgender Adults: Implications for Discrimination and Health. In Sociological Forum, vol.30:3, pp.809-831.

Maio, G. R., Olson, J. M., Bernard, M. M. \& Luke, M. A. (2006). Ideologies, Values, Attitudes and Behavior. In J. Delamater (Ed.), Handbook of Social Psychology (pp. 283-308). Springer.

Meyer, I. H. (2003). Prejudice, Social Stress and Mental Health in Lesbian, Gay, and Bisexual Populations: Conceptual Issues and Research Evidence. Psychological Bulletin, vol.129:5, p.674.

Nazir, N. \&Yasir, A. (2016). Education, Employability and Shift of Occupation of Transgender in Pakistan: A Case Study of Khyber Pakhtunkhwa. The Dialogue, vol.11:2, pp.158-158.

"Pakistan: Attacks on Transgender Women Surge", (2016). Retrieved from https://www.hrw.org/news/2016/08/22/pakistan-attacks-transgenderwomen-surge

Reisner, S. L., Conron, K. J., Tardiff, L. A., Jarvi, S., Gordon, A. R. \& Austin, S. B. (2014). Monitoring the Health of Transgender and Other Gender Minority Populations: Validity of Natal Sex and Gender Identity Survey Items in a US National Cohort of Young Adults. BMC Public Health, vol.14:1, p.1224.

Riaz, H. (1996). Socioecconomic Organization of Khusras. Unpublished M. Sc. Dissertation, Department of Anthropology, Quaid-i-Azam University, Islamabad, Pakistan.

Rodgers, S. M. (2017). Transitional Age Lesbian, Gay, Bisexual, Transgender, and Questioning Youth: Issues of Diversity, Integrated Identities, and Mental Health. Child and Adolescent Psychiatric Clinics of North America, vol.26:2, pp.297-309. 
Russell, S. T., Kosciw, J., Horn, S. \& Saewyc, E. (2010). Safe Schools Policy for LGBTQ Students. Social Policy Report. Volume 24, Number 4. Society for Research in Child Development.

Russell, S. T., Ryan, C., Toomey, R. B., Diaz, R. M. \& Sanchez, J. (2011). Lesbian, Gay, Bisexual and Transgender Adolescent School Victimization: Implications for Young Adult Health and Adjustment. Journal of School Health, vol.81:5, pp.223-230.

Sanchez, N. F., Sanchez, J. P. \&Danoff, A. (2009). Health Care Utilization, Barriers to Care and Hormone Usage among Male-to-Female Transgender Persons in New York City. American Journal of Public Health, vol.99:4, pp.713-719.

Sarfraz, A. (2017). Retrieved from Daily Pakistan: https://en.dailypakistan.com.pk/ headline/lhc-orders-to-include-transgender-persons-in-census/

Sharma, S. K. (2000). Hijras: The labelled deviance. New Delhi: Gyan Publishing House.

Sherriff, N. S., Hamilton, W. E., Wigmore, S. \& Giambrone, B. L. (2011). What do you say to them? Investigating and Supporting the Needs of Lesbian, Gay, Bisexual, Trans and Questioning (LGBTQ) Young People. Journal of Community Psychology, vol.39:8, pp.939-955.

Toomey, R. B., Ryan, C., Diaz, R. M., Card, N. A. \& Russell, S. T. (2010). Gender-Nonconforming Lesbian, Gay, Bisexual and Transgender Youth: School Victimization and Young Adult Psychosocial Adjustment. Developmental Psychology, vol.46:6, p.1580.

Totman, R. (2003). The Third Gender: Kathoey_-Thailand's labyboys. Bangkok, Thailand: Silkworm Books.

Valentine, D. (2007). Imagining Transgender: An Ethnography of a Category. Duke University Press.

Vance, S. R., Ehrensaft, D. \& Rosenthal, S. M. (2014). Psychological and Medical Care of Gender Nonconforming Youth. Pediatrics, vol.134:6, pp.1184-1192.

Van de Grift, T. C., Kreukels, B. P., Elfering, L., Özer, M., Bouman, M. B., Buncamper, M. E. \& Mullender, M. G. (2016). Body Image in Transmen: Multidimensional Measurement and the Effects of Mastectomy. The Journal of Sexual Medicine, vol.13:11, pp.1778-1786. 
Wolfradt, U. \& Neumann, K. (2001). Depersonalization, Self-Esteem and Body Image in Male-to-Female Transsexuals Compared to Male and Female Controls. Archives of Sexual Behavior, vol.30:3, pp.301-310.

Dr. Iram Batool is an Assistant Professor in the Department of Applied Psychology, Bahauddin Zakariya University, Multan.

Muhammad Saqib is Research Scholar in the School of Global and Urban Studies, RMIT University, Melbourne, Australia.

Abdul Sattar Ghaffari is Ph.D Scholar in the Department of Zhongtai Securities, Institute for Financial Studies, School of Mathematics, Shandong University, Jinan, Shandong, China. 